\title{
Study of MICS in Hemodialysis Patients and Its Relation with Serum Thyroid Hormones
}

\author{
Mohamed Omar Al Sayed Ali*, Mohammed Ali Fahmy El Zanaty, Tamer Mohamed Goda \\ Department of Internal Medicine, Faculty of Medicine - Zagazig University \\ *Corresponding Author: Mohamed Omar Al Sayed Ali, Mobile: (+20)01002284678, \\ Email: dr.mohamed2008@gmail.com
}

\section{ABSTRACT}

Background: Malnutrition-inflammation complex syndrome (MICS) is a frequent and serious problem in patients undergoing dialysis with estimated prevalence about $18-75 \%$. The etiology is multifactorial. MICS is believed to be main cause of erythropoietin hyporesponsiveness, low free triiodothyronine (FT3) and increased mortality and hospitalization among the dialysis patients.

Objective: To determine the prevalence of MICS and identify association between MICS and thyroid hormones.

Patients and Methods: This was cross sectional study, which was conducted on 91 patients admitted at Hemodialysis Units of Zagazig University Hospitals and Fakous General Hospital. Blood samples had been obtained before the initiation of the HD session and after an 8 hours fasting, blood measurements included: Serum urea, creatinine, TSH, T3, FT3 and FT4.

Results: This study showed that, prevalence of MICS was about $56 \%$. There was statistically significant difference between patients had MICS and patients without MICS regarding age, and duration of hemodialysis. There was no statistically significant difference between patients had MICS and patients without MICS regarding T3, T4, TSH. There was statistically significant difference between patients had MICS and patients without MICS regarding serum creatinine.

Conclusion: This study concluded high prevalence of malnutrition-inflammation complex syndrome on patients on dialysis. There was no association between MICS and thyroid hormones.

Keywords: Dialysis, Frequency, Malnutrition inflammation complex syndrome, Thyroid hormones.

\section{INTRODUCTION}

Malnutrition is a frequent and serious problem in patients undergoing dialysis with estimated prevalence about $18-75 \%$. It is referred as "malnutritioninflammation complex syndrome (MICS) or "energy protein wasting syndrome" (1).

MICS is a condition in which there is a loss of protein reserves and energy resulting from inflammatory and non-inflammatory causes in patients with chronic kidney disease $(\mathrm{CKD}){ }^{(2)}$.

The etiology is multifactorial including diet, oxidative stress, acidemia, blood loss by hemodialyzers and through feces, uremic medium and the effect of anabolic hormones. The possible causes of MICS include comorbid illnesses, oxidative and carbonyl stress, nutrient loss through dialysis, anorexia and a low nutrient intake, uremic toxins, a decreased clearance of the inflammatory cytokines, a volume overload, and dialysis-related factors ${ }^{(3)}$.

MICS is believed to be main cause of erythropoietin hyporesponsiveness, low free triiodothyronine (FT3), a high rate of cardiovascular atherosclerotic disease, a decreased quality of life, and increased mortality and hospitalization among the dialysis patients ${ }^{(4)}$. Low FT3 syndrome is defined as low FT3 with normal thyroid stimulating hormone (TSH) and normal or slightly reduced free thyroxine (FT4) level. This has been correlated with parameters of malnutrition and inflammation ${ }^{(4)}$.
In CKD, there is an alteration of the metabolism, distribution, degradation and excretion of thyroid hormones; the most commonly observed is a decrease in total triiodothyronine (T3) concentration ${ }^{(5)}$. The etiology of thyroid disorders in CKD is multifactorial and it is not entirely understood. There are a number of contributing variables: a decreased activity of deiodinase, reduction in the excretion of inorganic iodine, presence of uremic toxins, metabolic acidosis, malnutrition, use of heparin in hemodialysis (HD), advanced age, infection by hepatitis $\mathrm{C}$ virus and drugs (amiodarone, steroids, beta-blockers, lithium, rifampin, sunitinib, sorafenib, imatinib, among others). Some studies in CKD patients have found correlations between low concentrations of T3 with high concentrations of inflammatory markers (highly sensitive $\mathrm{C}$ reactive protein [hsCRP], interleukin 6 [IL-6]), malnourishment (decrease in serum prealbumin concentration), endothelial dysfunction, deterioration of cardiac function, poor survival and greater mortality from all causes. Other authors have shown that low serum concentrations of FT3 are associated with an increase in mortality, which is explained in part by its underlying association with poor nutritional status and inflammation ${ }^{(6)}$.

The study aimed to improve the quality of life and to decrease morbidity in hemodialysis patients by focusing on malnutrition-inflammation complex syndrome (MICS) and clarify the relationship between it and changes in serum thyroid hormones. 


\section{PATIENTS AND METHODS}

This was cross sectional study which carried out at Hemodialysis Units of Zagazig University Hospitals and Fakous General hospital.

\section{Inclusion criteria:}

Both male and female patients with more than three months on HD, three sessions/week, age between 18 and 69 years, and without known thyroid disease.

\section{Exclusion criteria:}

- Patients with less than three months on HD.

- Patients younger than18 years old.

- Patients older than 69 years old.

- Patients with known thyroid diseases.

- Patients taking drugs that affect serum thyroid hormones.

- Patients with chronic diseases except diabetes mellitus and hypertension.

- Patients with a positive panel for human immunodeficiency virus, hepatitis $\mathrm{B}$ or $\mathrm{C}$ virus, or with a documented infection in the previous 6 weeks.

- Patients with known neoplastic diseases

\section{Sample size:}

Assuming that total number of hemodialysis patients in hemodialysis units of Zagazig University Hospital and Fakous General Hospital is about 120 patients/year and prevalence of malnutrition is $53.9 \%{ }^{(3)}$, the sample was calculated to be 91 cases by using epiinfo.7 at confidence level $95 \%$.

\section{Sampling technique:}

The participants were randomized taken from patients admitted at hemodialysis units of Zagazig University Hospitals and Fakous General Hospital.

\section{Methods:}

All cases had undergone:

- Identification of the patients who were meeting the inclusion criteria.

- Full history taking.

- Full clinical examination.

\section{Laboratory Investigations:}

Blood samples had been obtained before the initiation of the HD session and after an 8 hours fasting, blood measurements included:

- Complete blood count (CBC).

- Blood glucose level.

- Serum urea, Creatinine.

- Serum ferritin, transferrin.

- Cholesterol, triglycerides.

- Albumin.

- IL-6.

- TSH, T3, FT3 and FT4
Malnutrition-inflammation complex syndrome (MICS) was determined according to the Malnutrition Inflammation Score (MIS) ${ }^{(7)}$.

Ethical considerations:

- An Official permission was obtained from Faculty of Medicine, Zagazig University.

- An official permission was obtained from Hemodialysis Units of Zagazig University Hospitals and Fakous General Hospital.

- An official permission was obtained from the Institutional Research.

- Approval from Ethical Committee in the Faculty of Medicine (Institutional Research Board IRB).

\section{Statistical Analysis}

Data entry, processing and statistical analysis was carried out using SPSS version 24. Data were expressed as mean \pm standard deviation ( $\tilde{\mathrm{x}} \pm \mathrm{SD})$ for numerical data and as frequency and percentage for non-numerical data. T-test was used to compare means.

P-values less than $0.05(5 \%)$ was considered to be statistically significant.

\section{RESULTS}

This table shows that mean age of the studied group was 52.3 and $57.1 \%$ were males (Table 1).

Table (1): Descriptive analysis

\begin{tabular}{|l|l|}
\hline & $\mathbf{N}=\mathbf{9 1}$ \\
\hline Age “years" & \\
$\tilde{\mathbf{x}} \pm$ SD & $52.3 \pm 12.7$ \\
\hline Gender & \\
Male & $52 \Rightarrow 57.1 \%$ \\
Female & $39 \Rightarrow 42.9 \%$ \\
\hline
\end{tabular}

Table (2) show the prevalence of MIC.

Table (2): Prevalence of MIC among the studied group

\begin{tabular}{|l|l|}
\hline & $\mathbf{N}=\mathbf{9 1}$ \\
\hline $\begin{array}{l}\text { Prevalence of MIC } \\
\text { N (\%) }\end{array}$ & $51(56.0 \%)$ \\
\hline
\end{tabular}

This table shows the mean T3, T4 and TSH among the studied group (Table 3 ).

Table (3): T3, T4 and TSH among the studied group

\begin{tabular}{|l|l|}
\hline & $\mathbf{N}=\mathbf{9 1}$ \\
\hline T3 & \\
$\tilde{\mathbf{x}} \pm$ SD & $0.9 \pm 0.28$ \\
\hline T4 & \\
$\tilde{\mathbf{x}} \pm$ SD & $1.4 \pm 0.08$ \\
\hline TSH & \\
$\tilde{\mathbf{x}} \pm$ SD & $2.70 \pm 0.3$ \\
\hline
\end{tabular}


Table (4) shows that there is high significant relation between MIC and age.

Table (4): Comparison between cases with MIC and cases without MIC regarding age.

\begin{tabular}{|l|l|l|c|}
\hline & $\begin{array}{l}\text { Without MIC } \\
\mathbf{N}=\mathbf{4 0}\end{array}$ & $\begin{array}{l}\text { With MIC } \\
\mathbf{N = 5 1}\end{array}$ & $\mathbf{P}$ \\
\hline $\begin{array}{l}\text { Age "years" } \\
\tilde{\mathrm{x}} \pm \text { SD }\end{array}$ & $45.5 \pm 14.4$ & $57.6 \pm 7.7$ & $<0.001^{* *}$ \\
\hline
\end{tabular}

Table (5) shows that there was high significant relation between MIC and months on hemodialysis.

Table (5): Comparison between cases with MIC and cases without MIC regarding Months on "HD"

\begin{tabular}{|l|l|l|c|}
\hline & $\begin{array}{l}\text { Without MIC } \\
\mathbf{N}=\mathbf{4 0}\end{array}$ & $\begin{array}{c}\text { With MIC } \\
\mathbf{N = 5 1}\end{array}$ & $\mathbf{P}$ \\
\hline $\begin{array}{l}\text { Months on "HD" } \\
\tilde{\mathbf{x}} \pm \text { SD }\end{array}$ & $39.4 \pm 9.2$ & $65.1 \pm 10.4$ & $<0.001^{* *}$ \\
\hline
\end{tabular}

This table shows that there was significant relation between MIC and systolic and diastolic blood pressure (Table 6).

Table (6): Comparison between cases with MIC and cases without MIC regarding systolic and diastolic blood pressure

\begin{tabular}{|l|c|l|l|}
\hline & $\begin{array}{l}\text { Without MIC } \\
\mathbf{N = 4 0}\end{array}$ & $\begin{array}{l}\text { With MIC } \\
\mathbf{N}=\mathbf{5 1}\end{array}$ & $\mathbf{p}$ \\
\hline $\begin{array}{l}\text { Systolic blood } \\
\text { pressure }\end{array}$ & $131 \pm 13.3$ & $137.7 \pm 11.8$ & $0.013^{*}$ \\
$\begin{array}{l}\tilde{\mathrm{x}} \pm \text { SD } \\
\begin{array}{l}\text { Diastolic } \\
\text { blood pressure } \\
\tilde{\mathrm{x}} \pm \mathrm{SD}\end{array}\end{array}$ & $78.5 \pm 10.4$ & $84.1 \pm 8.2$ & $0.005^{*}$ \\
\hline
\end{tabular}

Table (7) shows that there was significant relation between MIC and creatinine.

Table (7): Comparison between cases with MIC and cases without MIC regarding urea and Creatinine

\begin{tabular}{|l|c|c|c|}
\hline & $\begin{array}{c}\text { Without MIC } \\
\mathbf{N = 4 0}\end{array}$ & $\begin{array}{c}\text { With MIC } \\
\mathbf{N}=\mathbf{5 1}\end{array}$ & P \\
\hline $\begin{array}{l}\text { Urea } \\
\tilde{x} \pm \text { SD }\end{array}$ & $103 \pm 16.3$ & $115.1 \pm 19.6$ & 0.18 \\
\hline $\begin{array}{l}\text { Creatinine } \\
\tilde{x} \pm \text { SD }\end{array}$ & $7.5 \pm 1.3$ & $9.4 \pm 2.9$ & 0.001 \\
\hline
\end{tabular}

Table (8) shows there was no significant relation between MIC and T3, T4 and TSH.
Table (8) Comparison between cases with MIC and cases without MIC regarding thyroid hormones

\begin{tabular}{|l|c|c|c|}
\hline & $\begin{array}{c}\text { Without MICS } \\
\mathbf{N = 4 0}\end{array}$ & $\begin{array}{c}\text { With MICS } \\
\mathbf{N = 5 1}\end{array}$ & P \\
\hline $\begin{array}{l}\text { T3 } \\
\tilde{\mathrm{x}} \pm \mathrm{SD}\end{array}$ & $0.96 \pm 0.06$ & $1.01 \pm 0.04$ & 0.67 \\
\hline $\begin{array}{l}\mathrm{T} 4 \\
\tilde{\mathrm{x}} \pm \mathrm{SD}\end{array}$ & $1.26 \pm 0.08$ & $1.56 \pm 0.08$ & 0.08 \\
\hline $\begin{array}{l}\mathrm{TSH} \\
\tilde{\mathrm{x}} \pm \mathrm{SD}\end{array}$ & $1.99 \pm 0.1$ & $2.28 \pm 0.4$ & 0.3 \\
\hline
\end{tabular}

\section{DISCUSSION}

This study showed that, prevalence of MIC was about 56\%. This agrees with Chávez Valencia et al. ${ }^{(3)}$ who found frequency of MICS was $53.9 \%$. This is in similarity with Aggarwal et al. ${ }^{(8)}$ who revealed prevalence of MIC was $60 \%$. This disagrees with Gracia-Iguacel $\boldsymbol{e t} \boldsymbol{a l} .{ }^{(9)}$ who found prevalence of malnutrition was up to $80 \%$.

This study showed that, there was statistically significant difference between patients had MICS and patients without MICS regarding age and duration of hemodialysis. This agrees with Aggarwal et al. ${ }^{(8)}$ who found a positive correlation of MIC with the age. Zehra et al. ${ }^{(10)}$ revealed that moderate malnutrition complex syndrome (MICS) was higher in age groups of 31-40 years (14\%) as compared to $12 \%$ in $41-50$ years, $10 \%$ in $51-60$ years and $4 \%$ in over 60 years.

This study showed that, there was statistically significant difference. There was no statistically significant difference between patients had MICS and patients without MICS regarding T3, T4, TSH. Chávez Valencia et al. (3) note that, patients with MIC had higher serum concentrations of TSH and FT4 and lower serum concentrations of T3. In addition, they observed a positive association between MICS and serum concentrations T4L and negative association of MICS and serum concentrations T3 and T3L and they did not find an association of TSH with MICS.

In the present study, there was an association of higher blood pressure with MIC. Also Chávez Valencia et al. ${ }^{(3)}$ found in MIS survey, $53.9 \%$ of the patients had MICS; 55 of them had hypertension.

In the present study, there was an association between higher serum creatinine and MIC but this could not be verified with urea. This goes with the results presented by Aggarwal $\boldsymbol{e t}$ al. (8), where they found patients with malnutrition had higher level of blood urea and serum creatinine indicating that advanced renal failure leads to higher prevalence of malnutrition in comparison to early stage renal failure. 
High levels of blood urea, creatinine, uric acid and phosphate were associated with poor nutritional status. Moreover, iron deficiency anemias are associated with low serum ferritin levels. Serum ferritin, which is used as a marker of iron status, is also an inflammatory marker ${ }^{(8)}$.

On the other hand YapGharavian et al. ${ }^{(11)}$ stated that blood cholesterol and triglyceride levels were not significantly correlated with incidence of malnutrition. In addition, CRP index (depending on the amount of agglutination) had no significant effect in the incidence of malnutrition.

\section{CONCLUSION}

This study concluded high prevalence of malnutrition-inflammation complex syndrome on patients on dialysis. There was no association between MICS and thyroid hormones.

\section{REFERENCES}

1. Beddhu S, Wei G, Chen X et al. (2017): Associations of dietary protein and energy intakes with proteinenergy wasting syndrome in hemodialysis patients. Kidney International Reports, 2(5): 821-830.

2. Mitchell G (2015): Integration of primary care into the management of chronic pain. Pain: The person, the science, the clinical interface, edited by Patricia Armati and Roberta Chow. Melbourne, Australia, Pp. 278-289.

https://espace.library.uq.edu.au/view/UQ:381723

3. Chávez Valencia V, Mejía Rodríguez $\mathbf{O}$, Viveros Sandoval M et al. (2018): Prevalence of malnutritioninflammation complex syndrome and its correlation with thyroid hormones in chronic haemodialysis patients. Nefrología (English Edition), 38(1): 57-63.
4. Vlatković V, Trbojević-Stanković J, Stojimirović B (2017): Relationship between malnutritioninflammation complex syndrome and fluid balance in maintenance hemodialysis patients. Urol Nephrol Open Access J., 4(5): 00144.

5. Kastanias $\mathbf{P}$, Mackenzie $\mathrm{K}$, Robinson $\mathrm{S}$ et al. (2017): Medical complications resulting from severe obesity. In Psychiatric Care in Severe Obesity. Springer, Cham., Pp. 49-73. https://link.springer.com/chapter/10.1007/978-3-31942536-8_5

6. Singh S, Verma A, Aryal G et al. (2016): Thyroid hormone profile in patients with chronic kidney disease: a single centre study. J Nepal Health Res Counc., 14(34):197-201

7. Kalantar-Zadeh K, Kopple J, Block G et al. (2001): A malnutrition-inflammation score is correlated with morbidity and mortality in maintenance hemodialysis patients. Am J Kidney Dis., 38(6):1251-1263.

8. Aggarwal H, Jain D, Chauda $\mathrm{R}$ et al. (2018). Assessment of malnutrition inflammation score in different stages of chronic kidney disease. PRILOZI, 39(2-3): 51-61.

9. Gracia-Iguacel C, González-Parra E, PérezGómez M et al. (2013). Prevalence of protein-energy wasting syndrome and its association with mortality in haemodialysis patients in a centre in Spain. Nefrología (English Edition), 33(4): 495-505.

10. Zehra K, Mal P, Kumar D et al. (2014): Frequency of malnutrition inflammation complex syndrome in patients with end stage kidney disease on maintenance hemodialysis presenting to tertiary care Hospital, Karachi. Journal of the Liaquat University of Medical and Health Sciences, 13(3):101-105.

11. YapGharavian A, Dorri A, Ebrahimzadehkor B (2014): Malnutrition-Inflammation Score in Hemodialysis Patients. Zahedan Journal of Research in Medical Sciences, 16(8)25-28. 